\title{
PERFORMANCE OF A DIRECT EVAPORATIVE AIR COOLER
}

\author{
A.R.El-Ghalban, M.A.Habib, A.H. Farag, and T.A.Shalma \\ Dept. of Mech. Power Engineering, Faculty of Engineering-Shebin El-kom \\ Minoufiya University, Shebin El-kom, Egypt
}

\begin{abstract}
The thermal performance of a direct evaporative air cooler (DEAC) is analyzed numerically and experimentally. The effects of a wide variety of parameters such as air velocity, water velocity, the inlet and outlet relative humidity on the thermal performance of the (DEAC) are investigated. A simple mathematical model for countercurrent evaporative cooler is presented. The model consists of ordinary differential equations(ODE), which describe the mass and heat exchange processes in addition to the mass energy and momentum conservation laws. The model include the necessary equations, which present the problem's initial and boundary conditions. The model inputs include the inlet temperature and the mass flow rates of both air and water, and the relative humidity of air at its inlet The predicted values for air and water exit properties, for given input conditions, agree well with experimental data obtained for the direct evaporative cooler.
\end{abstract}

نستخدم طريقة التبريد التبخيرى في كثير من التطبيقات المهنسية و في هذه الطريقة يستخدم الماء إما على هينسة

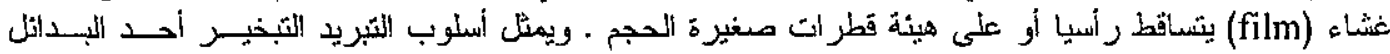

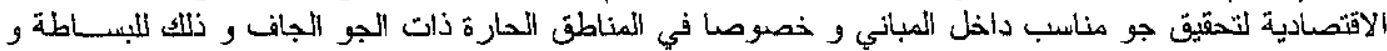

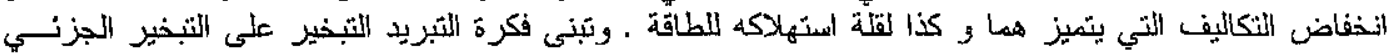

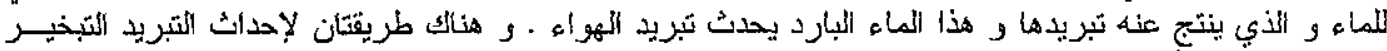

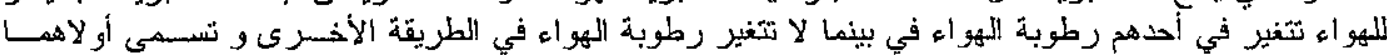

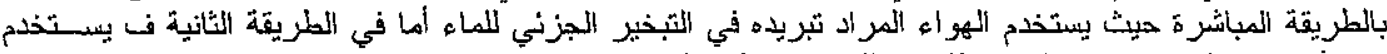

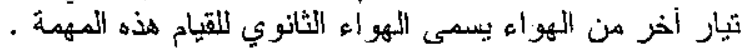

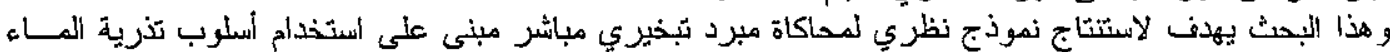

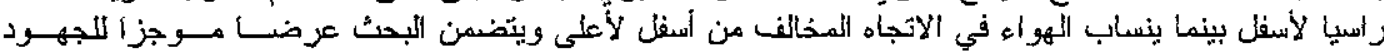

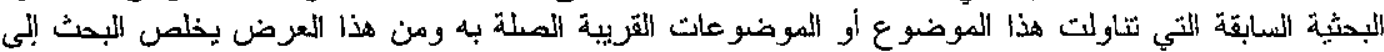

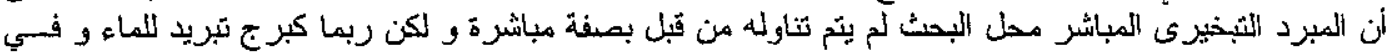

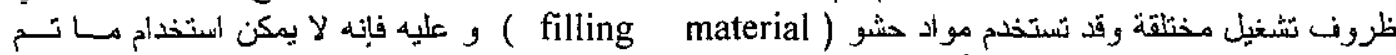

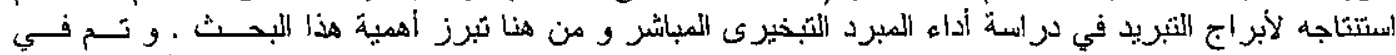

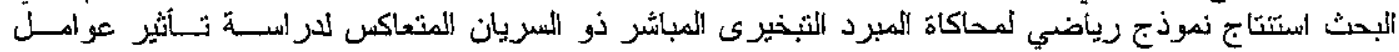

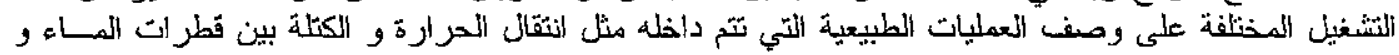

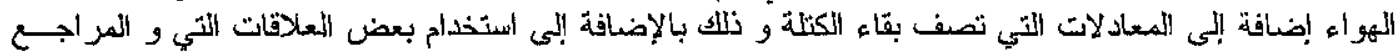

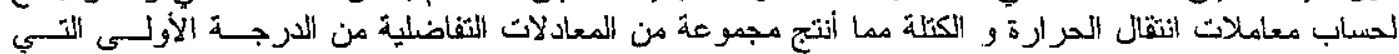

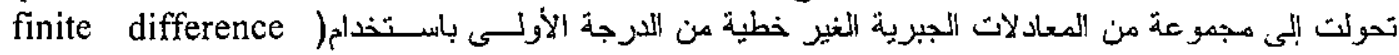

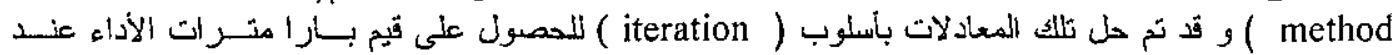

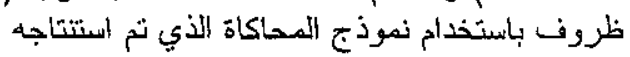

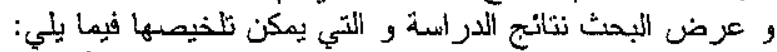

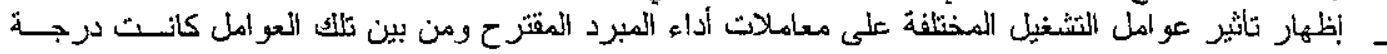

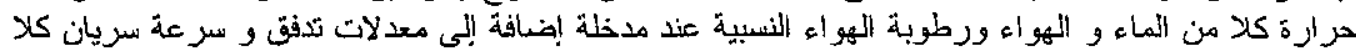

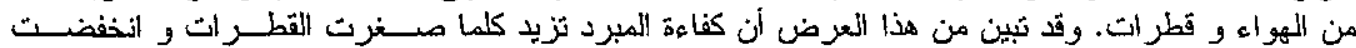

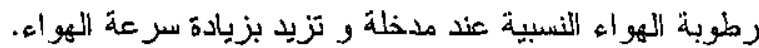

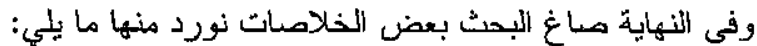

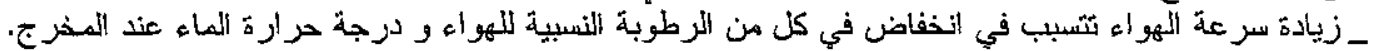

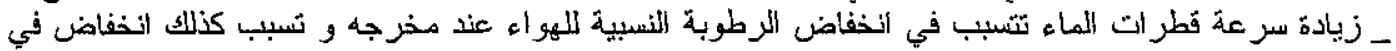

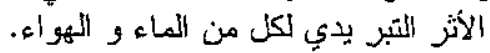

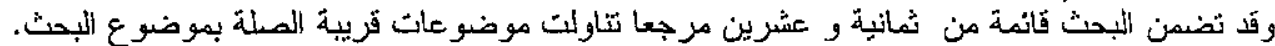

Keywords: Cooling Tower, Direct Evaporative Air Cooler, Mass and Heat Exchange Processor.

Engineering Research Journal, Vol.28, No. 3 July 2005, PP 253-266 


\section{NOMENCLATURE}

$A_{s} \quad$ Surface area of water droplet

$C_{d} \quad$ Coefficient of drag

$C_{p a} \quad$ Specific heat of air at constant pressure

$C_{p, a v} \quad$ Average specific heat of air

$C_{p d} \quad$ Specific heat of droplet

$D \quad$ Droplet diameter

$g \quad$ Constant for gravity

$h$ Heat transfer coefficient

$h_{c} \quad$ Convective heat transfer coefficient of air

$h_{D} \quad$ Convective mass transfer coefficient of water

$h_{f g} \quad$ Enthalpy of evaporation

$h_{f g, 0} \quad$ Enthalpy of evaporation at $0^{\circ} \mathrm{C}$

$h_{m} \quad$ Mass transfer coefficient

$k_{a} \quad$ Thermal conductivity of air

$L \quad$ Length

Le Lewis number

$\dot{m} \quad$ Mass flow rate

$n$ Number of drops per second per unit cross-section area of duct

$N \quad$ Number of drops per second

$\mathrm{Nu} \quad$ Nusselt number

$p \quad$ Pressure at the cross-section of the duct

$p_{v s} \quad$ Saturation pressure corresponding to air

$\operatorname{Pr} \quad$ Prandtl number

$Q_{a c t} \quad$ Actual nozzle discharge

$\mathrm{Re}_{d} \quad$ Droplet Reynolds number

Sc Schmidt number

Sh Sherwood number

$T$ Temperature

$u_{a} \quad$ Air velocity inside the duct

$U_{d} \quad$ Droplet velocity

$X \quad$ Mass fraction of water vapor in air

$X$. Mass fraction of water vapor at the droplet surface

$Y \quad$ Positive direction along the duct

\section{Greek letters}

$\begin{array}{ll}\delta & \text { Mass diffusivity of vapor in the moist air } \\ \phi & \text { Relative humidity } \\ \lambda & \text { Ratio of air to vapor molecular weight } \\ \mu & \text { Dynamic viscosity } \\ \rho & \text { Density } \\ \omega & \text { Humidity ratio }\end{array}$

\begin{tabular}{cl}
\multicolumn{2}{l}{ Subscripts } \\
0 & Initial \\
a & Air \\
d & Droplet \\
e & Evaporation \\
i & Inlet \\
w & Water \\
av & Average \\
db & Dry-bulb \\
s & Saturation, Surface \\
wb & Wet-bulb \\
Cal. & Calculated
\end{tabular}

\section{INTRODUCTION}

Evaporative cooling is a simple and effective way of cooling an air stream. In a direct evaporative cooler, the air stream to be cooled is in direct contact with a liquid water film or spray and cooling is accomplished by the adiabatic heat exchange between the air stream and the liquid water film or water droplets spray. The evaporation of water in the air stream leads to a reduction in the dry-bulb temperature and water temperature. However, this will also concurrently cause an increase of the humidity ratio of the air stream. Generally, the maximum possible reduction in air dry-bulb temperature depends on the difference between the dry-bulb and the wet-bulb temperature of the air stream. In many applications, however, the increase of humidity in a supply air stream is not desirable. The cooling is accomplished by an adiabatic heat exchange between the air stream and the water. As another field of usage, evaporative cooling devices are used to reject waste heat to the environment in cooling towers, evaporative condensers and evaporative fluid coolers. In comparison with other systems, the evaporative coolers are characterized by small investment and exploitation cost in addition to its economical use of materials. Therefore it could be said that, evaporative air coolers could be used to save part of the increasing energy demand in space cooling sector. Sprays or falling film methods are commonly used as a wetting technique either in counter, parallel or cross flow configuration to the airflow in such applications.

\section{LITERATURE REVIEW}

The study of air-water interaction involves many fields of engineering applications, namely spray, falling film, hydrodynamics, multiphase flow and heat and mass transfer. Following, is a review of the obtained literature found concerning with these applications. Fisenko et al. [1] presented mathematical model of the performance of a cooling 
tower. They show by comparison between experimental data and calculated results that the model correctly describes the basic regularities of the cooling tower performance. Petruchik et al. [2] developed a new mathematical model of a mechanical draft cooling tower performance. Their model describe the change in the droplets velocity, its radii and temperature, and also the change in the temperature and density of the water vapor in a mist of air in a cooling tower. Brin et al. [3] proposed a mathematical model of the operation of a mechanical-draft tower. The basic parameters such as temperature of inflowing water, its discharge, mean radius of water droplets, mean air velocity inside the water-cooling tower etc. were influencing the tower thermal efficiency. Al-Juwayhel et al. [4] investigated experimentally the thermal effectiveness and the air-side pressure drop of single- and twostage evaporative coolers. They had tested two different configurations of the two-stage evaporative cooler. The first one used, indirect water-to-air precooler and the second cooled water in the directcontact evaporative cooler. Boris Halasz [5] presented a general nondimensional mathematical model for the description of all types of evaporative cooling devices. For every type an unique rating procedure can be established. Pearlmutter-D et al. [6] studied direct evaporative cooling as an energyefficient and cost-effective means for space conditioning in hot dry areas. They described the development of the cooling tower system. Al-Nimr [7] described the dynamic thermal behavior of a counter flow-cooling tower. The model takes into account both sensible and latent heat cooling effects on the tower performance. Kachbwaha et al. [8] investigated experimentally and numerically evaporative cooling of air with a water spray for horizontal parallel flow, and horizontal counter flow. They used a hollow cone water sprays. They developed two-dimensional numerical model simulating the conservation of mass, momentum and energy of air and water for predicting the heat and mass transfer in these spray air flow systems. Harlow et al. [9] described numerical solutions of the governing equations of gas-liquid spray systems which could be obtained by finite difference methods. Emam et al.[10] introduced an analytical method for predicting the rate of evaporation of liquid spray droplets into a high temperature gas stream. An experimental verification of the predicted results is carried out. They developed an optical arrangement for measurements of size distribution of spray droplets injected into a high temperature Stream of air. Goshayshi et al. [11] investigated experimentally the effect of form with corrugated packing on mass transfer and pressure drop characteristics in atmospheric cooling towers. The results showed that the mass transfer coefficient decreased with increasing the packing pitch and increasing the ratio of rib pitch to rib height. Dreyer et al. [12] developed a mathematical model and a computer simulation program to predict the performance of counter flow cooling tower splash packing material. The program could be used to evaluate different splash pack designs without making use of empirical data from splash pack tests. Maiya [13] discussed a two modified cooling towers and their thermal performances are compared with the conventional counter-flow cooling tower, and presented the results in terms of number of transfer units (NTU). Majumar et al. [14] (partl) discussed the limitations of current practices of evaluating thermal performance of wet cooling towers and describe a more advanced mathematical model for mechanical and natural draft cooling towers. ElGhalban. [15] discussed heat and mass transfer processes in adiabatic evaporative coolers, by presenting a simple mathematical model for countercurrent evaporative cooler. The effect of various parameters such as the inlet temperature of water droplets etc. is presented. El-Dessouky et al [16] evaluated the thermal and hydraulic performance of a modified two-stage evaporative cooler. Variables considered were the mode of operation, packing thickness, mass flow rate of the water flowing to the precooler, and the mass flux of water flowing over the packing media. Fisenko et al.[17] developed a mathematical model of the control system for the film type counter-flow mechanical draft cooling tower. Various regimes of cooling tower performance are compared and the optimization method is proposed. Khan et al. [18] presented a fouling model using the experimental data on fill fouling, which used to investigate the risk based thermal performance of the cooling tower. Prasad [19] presented a novel numerical experimental technique for modular performance evaluation of multi-cell cross flow evaporative water cooling tower of single-flow design that determines fill characteristic for individual cell half with total system in operation. Girish et al. [20] presented a numerical technique for evaluating the performance of forced convective evaporation system for tannery effluent. They developed a mathematical model, which treats the airflow as two-dimensional and liquid flows as one-dimensional.

From this brief review of literature relevant to the present study it is clear that available $r$ ported work on the investigation of the adiabatic evaporative water air coolers is little. Most of the available published studies have been carried out either for the modeling of cooling towers which operate under different circumstances and may have different packing properties, or for the modeling of fluid evaporative heat exchangers, where the fluid to be cooled flows inside a heat exchanger while the other side of the heat exchanger is wetted with water film 
to be evaporated with the flowing air to achieve the desired cooling effect. Another group of the published work is concerned with the flow field of the different water spray configurations or droplet trajectory.

\section{MATHEMATICAL MODEL}

The objective of this study is to analyze the characteristics of vertical counter-flow evaporative air cooler. A mathematical model is developed to describe the mutual heat and mass transfer processes between water and air that occurs in such systems. Figure-1-a presents a schematic diagram of the evaporative air cooler. Air is forced to flow in the direction opposite to the water flow direction through the cooler duct. Figure $1-b$ shows the considered control volume where air flows upwards through the lower border to the control volume while the droplet stream flows downwards though the upper border. The heat and mass exchange between air and water droplets takes place at the interface of the droplets. The coordinate system for both streams is shown in Figure 1-a with the origin at the droplet inception point. The mass, momentum and energy conservation equations for the configuration given in Figure $1-b$ result in a system of first order differential equations which are solved using finite difference technique over the droplet and air paths. The performance analysis of the direct evaporative cooler and the derivation of the mathematical model described below is based on the following assumptions.

1. The heat and mass transfer processes are performed at steady state conditions.

2. Heat and mass transfer coefficients are considered constant throughout the flow path.

3. The thermo physical properties of air and water are considered constant over the working temperature range.

4. Air is thoroughly mixed i.e. the air temperature and humidity are constant in any given horizontal plane.

5. There is no temperature gradient within the water droplet.

6. At the interfacial surface, air reaches the temperature of water droplets and its humidity corresponds to the state of equilibrium.

7. The temperature change for each water and air as well as humidity change is in the direction of flow only.

The effect of the assumption that the water interface temperature is equal to the bulk water temperature has been investigated by Baker and Shryock. [21], Webb et al. [22] and Marseille [23].

\subsection{Conservation Equations}

The mass, momentum and energy conservation equations which comprise the model, are described below.

\subsubsection{Conservation of mass:}

The conservation of water vapor mass in air can be expressed as the increase in mass and mass fraction of water in the air water mixture $(X)$ that occurs due to evaporation of drops, wet evaporative cooler surfaces:

$$
\frac{d X}{d y}=\sum \frac{n h_{m} A_{s}\left(X_{s}-X\right)}{U_{d} u_{a}}
$$

Similarly, conservation of mass for air can be written as :

$$
\rho_{a}(1-X) u_{a} A=\text { constant }
$$

\subsubsection{Conservation of Momentum.}

For air, the conservation of $y$-momentum represents the balance of air acceleration with momentum addition from drops, change of mass (due to evaporation from drops), pressure gradient in duct and wall shear stresses [24]. In the present model air pressure in the wind tunnel was assumed constant throughout the duct. Momentum exchange between air and droplets has also been assumed to be negligible and, therefore, the air momentum equation is not used in the simulations.

The deceleration of drops in the $y$-direction can be expressed as follows:

$$
\begin{aligned}
\frac{d U_{d}}{d y}= & \frac{g\left(\rho_{d}-\rho_{a}\right)}{U_{d} \rho_{d}}-\frac{0.75 C_{d} \rho_{a}\left(U_{d}-u_{a}\right)}{\rho_{d} D U_{d}} \\
& -\frac{3 U_{d} h_{m} \rho_{a}\left(X_{s}-X\right)}{\rho_{d} D U_{d}}
\end{aligned}
$$

The right-hand side of this equation gives the buoyancy, drag and the inertia force occurring due to the change in droplet mass.

\subsubsection{Conservation of energy:}

Change in air temperature occurs due to mass and heat transfer from drops and from the walls which can be expressed as follows:

$$
\begin{gathered}
\frac{d T_{a}}{d y}=\sum \frac{\left[n h_{f g} \pi D^{2} h_{m} \rho_{a}\left(X_{s}-X\right)\right.}{C_{p, a v} \rho_{a} u_{a} U_{d}} \\
-\frac{\left.n h \pi D^{2}\left(T_{a}-T_{d}\right)\right]}{C_{p, a v} \rho_{a} u_{a} U_{d}} \\
-\frac{h_{f k, 0}}{C_{p, a v}} \frac{d X}{d y}
\end{gathered}
$$

The number of drops is calculated by the following relation:

$$
N=\frac{6 Q_{a c t}}{\pi D^{3}}
$$


Energy balance on drops represents the rate of change of drop temperature, and the mass and heat transfer occurring with air.

$$
\begin{aligned}
\frac{d T_{d}}{d y}= & \frac{6\left[h\left(T_{a}-T_{d}\right)-h_{f g} h_{m} \rho_{a}\left(X_{s}-X\right)\right.}{D \rho_{d} U_{d} C_{p d}} \\
& \frac{\left[3 h_{d} h_{m} \rho_{a}\left(X_{s}-X\right)\right]}{D \rho_{d} U_{d} C_{p d}}
\end{aligned}
$$

\subsection{Correlations used}

\subsubsection{Drag coefficient:}

Here each droplet is assumed to behave like a rigid sphere for which drag coefficient-Reynolds number relations are available. For ease of computation, the correlations of Linn et al. [25] have been used:

$$
\begin{aligned}
& C_{d}=24\left(\operatorname{Re}_{d}\right)^{-i} \quad \text { for } \quad \operatorname{Re}_{d}<2 \\
& C_{d}=18.197\left(\operatorname{Re}_{d}\right)^{-0.599} \text { for } 2<\operatorname{Re}_{d}<500 \\
& C_{d}=0.44 \text { for } 500<\operatorname{Re}_{d}<2 * 10^{5}
\end{aligned}
$$

Here, $\operatorname{Re}_{d}$ is the drop Reynolds number based on velocity of drops relative to the air which is expressed as:

$$
\operatorname{Re}_{d}=\frac{\rho_{a}\left(U_{d}+u_{a}\right) D}{\mu_{a}}
$$

\subsubsection{Mass concentration properties:}

The mass concentration of water vapor at the drop surface is given by:

$$
X_{s}=\frac{p_{u s s}}{\lambda p-(1-\lambda) p_{v s}}
$$

where, $\lambda$ is the ratio of the air to vapor molecular weight, $p_{v s}$ the partial pressure of water vapor and $p$ the total atmospheric pressure. For air water vapor mixture, $\lambda$ is equal to 1.608 . In general, $p_{x \in}$ can be approximated by the saturation pressure corresponding to the drop temperature.

The mass fraction of water vapor in air can be expressed as:

$$
X=\frac{\omega}{1+\omega}
$$

where, $\omega$ is humidity ratio, which is related to the saturation pressure, $p_{v s}$, and relative humidity, $\phi$, at the drop temperature by the following expression [26].

$$
\omega=\frac{0.62198 F S(T) \phi p_{v s}}{p-F S(T) \phi p_{v s}}
$$

then

$$
\phi=\frac{p \omega}{F S(T) p_{v s}(0.62198+\omega)}
$$

where,

$p=101325 \mathrm{~N} / \mathrm{m}^{2}$

$F S(T)=1.0046$ for $\mathrm{T} \geq 0.0$

$F S(T)=1.0044$ for $T \geq 4.0$

$F S(T)=1.0044+0.0002 /\{11(T-16)\}$ for $T>16.0$

$F S(T)=1.0046+0.0004 /\{11(\mathrm{~T}-27)\}$ for $T>27.0$

$F S\{T)=1.0046+0.0004 /\{11(\mathrm{~T}-33)\}$ for $T>38.0$

Temperature $\mathrm{T}$ is in ${ }^{\circ} \mathrm{C}$. Saturation pressure of water, $p_{w w}$, corresponding to temperature, $T$ is given by $S$. S. Kachbwaha [8] as follows:

$$
\begin{aligned}
p_{v s:}=\exp [ & -5800.2206 / T+1.3914993 \\
& -0.048640239 T+0.41764768 * 10^{-4} T^{2} \\
& -0.14452093 * 10^{-7} T^{3} \\
& +6.5459673 * \log T]
\end{aligned}
$$

\subsubsection{Heat and mass transfer correlations:}

The heat and mass transfer coefficient for drops have been determined from the correlations obtained from the present experimental results using the least square method:

$$
\begin{aligned}
& S h=\frac{h D}{\delta}=2.36869 * 10^{-4} \operatorname{Re}_{d}^{1.596} S c^{5.276}(16) \\
& N u=\frac{h D}{k_{a}}=3.482516 * 10^{-3} \operatorname{Re}_{d}^{0.012 T_{a}} \operatorname{Pr}^{-0.00021 T_{a}}
\end{aligned}
$$

where, Sc and $\mathrm{Pr}$ are the Schmidt, Prandtl number for air, which are defined as

$$
\begin{aligned}
& S c=\frac{\mu_{a}}{\rho_{a} \delta} \\
& \operatorname{Pr}=\frac{C_{p a} \mu_{a}}{k_{a}}
\end{aligned}
$$

where, $\mu_{a}, C_{p a}$ and $k_{a}$ are dynamic viscosity, specific heat and thermal conductivity of air at temperature $T_{a}$, and have been determined from the property data given by Dewitt and Incropera [27].

The mass diffusivity of water vapor in air, $\delta$, has been estimated from the relation developed by Bird et al. [28]:

$\delta=2.495 * 10^{-5}\left(\frac{T_{a}}{292.88}\right)^{2,334}$

Based on the heat balance equation between the convection heat and a droplet heat exchanges, the 
following equation for droplet evaporation temperature, $T_{e}$, is reached:

$$
T_{e}=T_{a}-\frac{\rho_{s:} h_{f g}}{\rho_{a} C_{p, a v} L e^{\frac{2}{3}}}
$$

where $\rho_{s}$, is the dry saturated vapor density at $T_{e}$, and Le is the Lewis number $\left(L e=h_{c} / h_{p} C_{p a}\right.$ ). $T_{v}$ is estimated using equation (16) by trial and error. The rate of vaporization of a spray droplet $m_{e}$ is calculated from the following relation;

$\dot{m}_{e}=\frac{\pi D N u}{h_{f z}} k_{a}\left(T_{a}-T_{\varepsilon}\right)$

$\mathrm{T}_{\mathrm{e}}$ and $\dot{m}_{e}$ has been investigated by S.H. El-Emam [10]

\section{RESULTS AND DISCUSSION}

The results obtained from our numerical approach and the experimental investigations carried out within this study for counter flow spray evaporative cooler (CFSEC) are presented in this section. The numerical results are based on an iterative procedure used to solve the governing equations. As a first approximation the droplet properties could be assumed constant throughout the duct and the air properties can be then computed by marching the iteration solution along the flow direction of air. Now the water properties can be calculated by marching the iteration solution in the water flow direction using the approximately known distributions for air properties.

The experimental results obtained by changing the operating conditions of the water mass flow rates, air velocity, inlet air dry bulb temperature, inlet water temperature, as well as the inlet relative humidity .

Figure(2) shows the layout of the test rig. It shows the components of air cooler unit and evaporative cooler. It consists of an air handler and complete refrigerator system entirely contained on one mobile A-frame. The air handler is divided into seven segments. These are:

- A Multi-speed, Direct Drive Blower. This blower is rated at $1705 \mathrm{CFM}$.

- Resistance Duct Heaters. There are two, twoelement duct heaters each heater rated at $2 \mathrm{KW}$. The elements are rated at $1 \mathrm{KW}$ each and are separately controlled.

- The steam injector provides low-pressure steam supplied from the boiler below the air handler. The boiler contains three immersion heaters rated at 1 $\mathrm{KW}$ and $2.5 \mathrm{KW}$. Each heater is separately controlled.
**This device is not used in this work.

- The duct evaporator provides up to 1/2-ton cooling capacity.

- Resistance Duct Heater. There are one, twoelement duct heater rated at $1 \mathrm{KW}$. Each element is $0.5 \mathrm{KW}$, which is separately controlled.

- The refrigeration system includes a $1 / 2 \mathrm{HP}$ compressor and condensing unit, a hot gas solenoid for quickly drying the evaporator, and the fully enclosed plenum evaporator that was previously mentioned. Pressure and temperature gauges are fixed to both the suction and liquid lines.

- The compressor, blower, heater and hot gas solenoid are controlled from a single switch panel located at the front of the trainer.

Evaporative cooler.

Body made of acrylic consists of the following parts:

- Eliminators: the evaporative cooler contains three eliminators (galvanized steel).

- Exhaust Fan (Q 40 lit./min , 0.45 HP ,2850 rpm, 330 watt)

- Pump (1 HP).

- Spray nozzles with adjust screw to control the flow rate of water.

- Orifice which is made of plate of steel .

Consequently, the experimental results highlight the properties of the moist air that was casted in three subsections in view, variations of relative humidity, air dry bulb temperature at outlet and variations of absolute humidity ratio at outlet.

The experimental procedure was carried out during summer where the climate is characterized by a high ambient temperature, so that the ambient conditions varied from 35 to $42^{\circ} \mathrm{C}$ and $22-80 \%$ relative humidity . ambient water temperature during these months was in the range of $26-33^{\circ} \mathrm{C}$. the measurements were performed for three air velocities namely, $0.8,1.6$ and $2.5 \mathrm{~m} / \mathrm{s}$.

The computations were carried out for inlet air temperature ranging from 25 to $60^{\circ} \mathrm{C}$, relative humidity ranging from 10 to $90 \%$. droplet diameter of $70 \mathrm{micron}$ and air velocity $1.1 \mathrm{~m} / \mathrm{s}$ to $1.45 \mathrm{~m} / \mathrm{s}$ and water velocity from 1.1 to $8 \mathrm{~m} / \mathrm{s}$ and water mass flow rates adjusted to be $20.4,9.82,7.28$ and $2.7 \mathrm{~g} / \mathrm{s}$.

Relative humidity is calculated using the readings of dry and wet-bulb thermometers. Water flow rate is determined with an orifice meter with U-tube manometers while the air velocity was measured by a cup anemometer. 


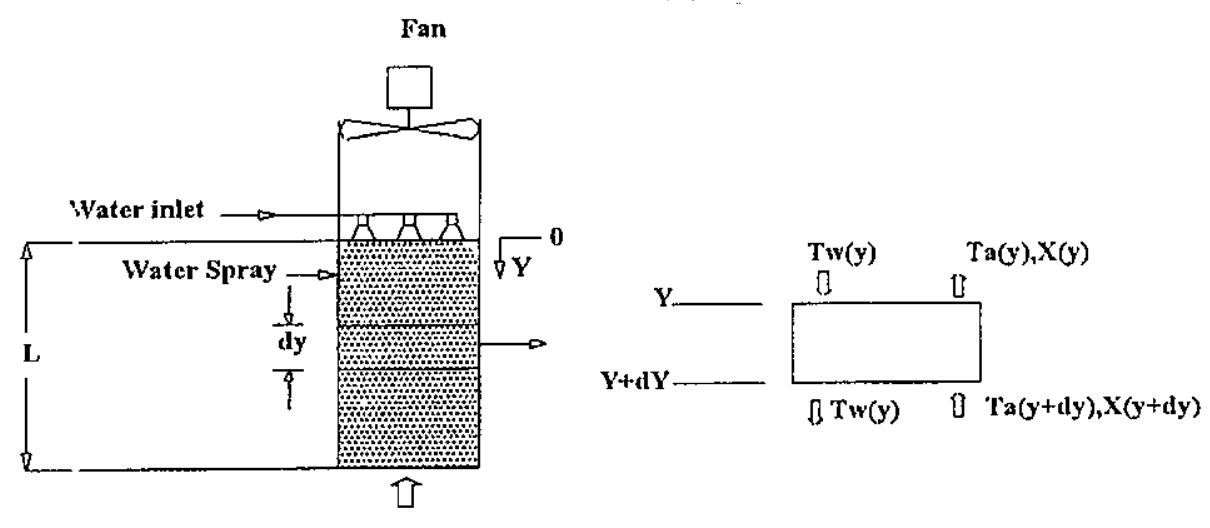

Air Inlet

Fig. 1-a Layout of the direct evaporative cooler

Fig. 1-b Schematic diagram of the control volume

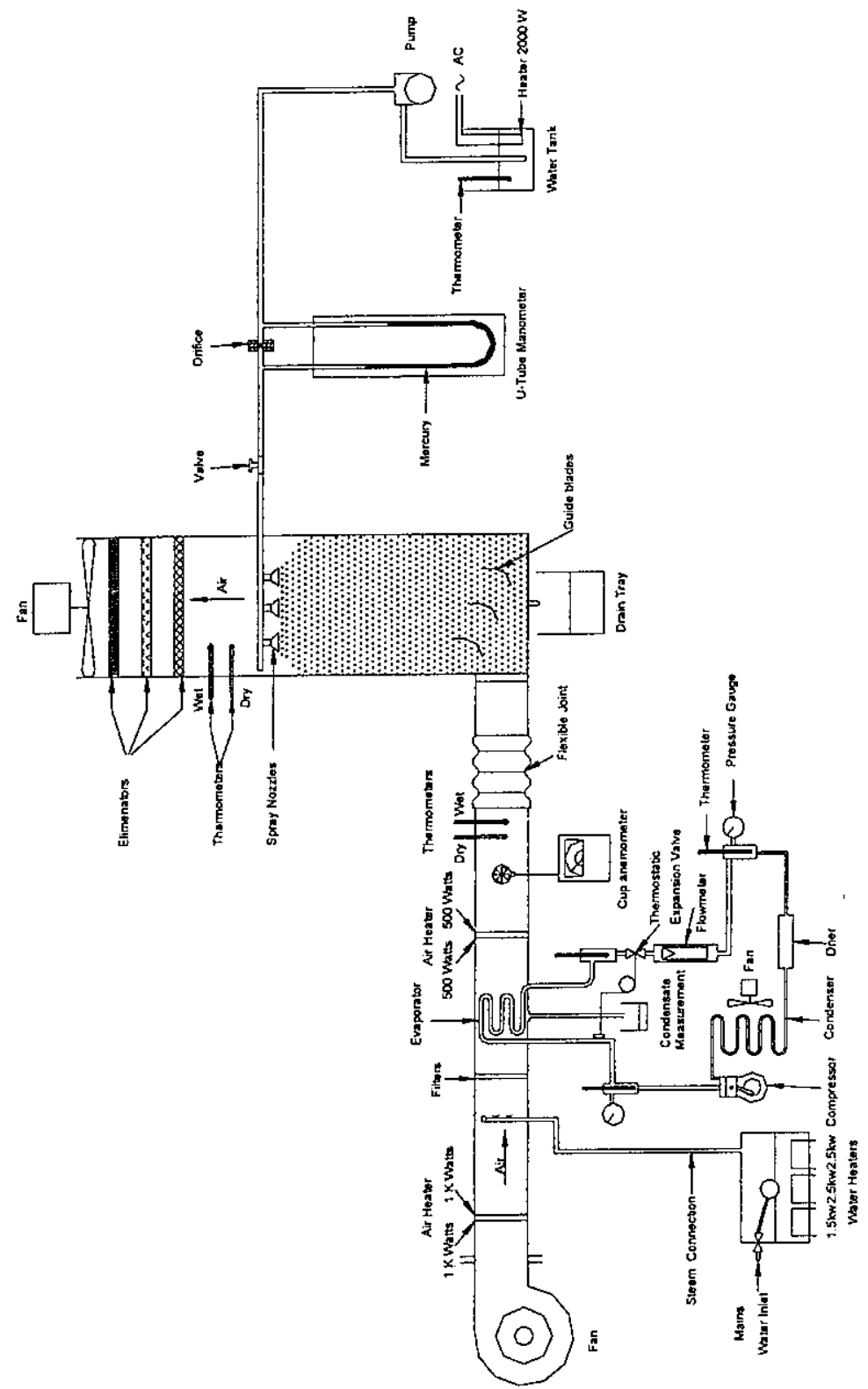

Fig. 2 Layout of the Test Rig 
1) The effect on the relative humidity at outlet.

The influence of air dry bulb temperature, and water temperature at inlet on the relative humidity at outlet is displayed in Figures 3 and 4 . Figure 3, shows that the experimental results agree well with the calculations. The maximum difference between the experimental and the theoretical obtained results is $5.8 \%$. Figure 3 -a explains the relation between air dry bulb temperature at inlet with the variations of relative humidity at outlet. The figure shows that as water temperature at inlet increases, the exit relative humidity decrease for assigned values of air dry bulb temperature at inlet. Figure $3-b$ shows that the relative humidity at outlet was enhanced by $(8 \%)$ as the water mass flow rates decreases by $(64 \%)$ for a range of air dry bulb temperature at inlet from $\left(30^{\circ} \mathrm{C}\right.$ to $55^{\circ} \mathrm{C}$ ). In comparison between Figure 3-b and Figure $3-c$, it is seen that the relative humidity was enhanced $(19 \%)$ as the air velocity decrease from $(1.3$ to $1.1 \mathrm{~m} / \mathrm{s})$. This could be attributed to the fact that as the air temperature is increased the required water vapor to reach saturation increases; meanwhile the increase in evaporation is limited by the mass transfer mechanism. Therefore, the increase in air temperature causes a decrease in relative humidity at outlet. In the same manner, the water temperature decrease will lead to a reduction in the relative humidity at outlet. Figure 3-c illustrates that as the water temperature increases, the relative humidity increases and then decreases with more increase of water temperature, this could be explained as follows. As the temperature difference between air and water increases the water vaporizes, in the same time the required water vapor to reach saturation increases too, so that the relative humidity will in turn increase. But as the temperature difference between air and water reaches the maximum value, and the mass flow rate is low, that will lead to a decrease in water vapor. The required water vapor to reach saturation for an assigned air dry bulb temperature increases, so the relative humidity decreases.

Inlet water temperature presents one of the important parameters; it affects the performance of an evaporative cooling system. Figures $4-a, b$ and $c$ describe the variation of relative humidity at outlet versus the water temperature at inlet for different air velocities. The subtle rise in relative humidity at outlet for different inlet air-dry bulb temperature varies according to the reduction in air mass flow rate. As is shown, the effect of water temperature at inlet is insignificant, on the relative humidity of air at outlet compared to that effect of air inlet temperature or air inlet velocity.
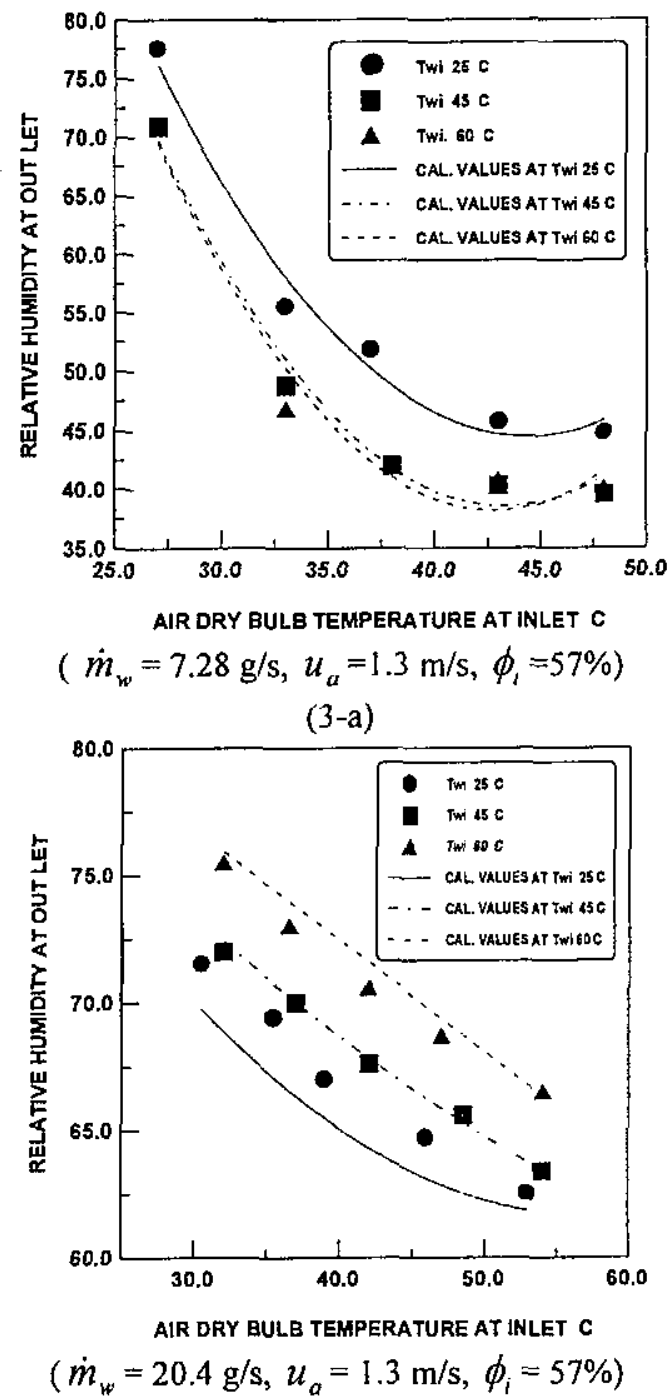

(3-b)

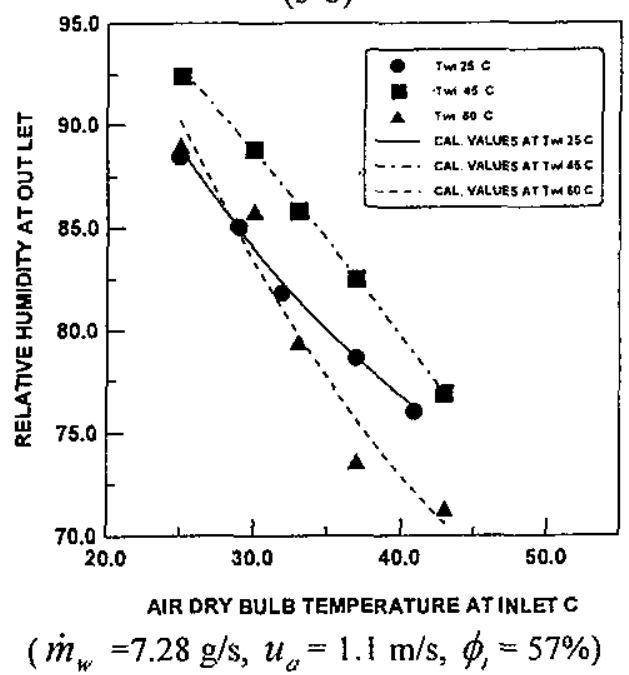

$(3-c)$

Fig 3. The effect of inlet temperature of air on the relative Humidity at outlet. 
The figures illustrate that the variation of relative humidity at outlet decreases as the water mass flow rate decreases. The comparison among Figures $4-a, b$ and $c$ show that as air velocity decreases from 1.45 to $1.1 \mathrm{~m} / \mathrm{s}$ through $1.3 \mathrm{~m} / \mathrm{s}$, the relative humidity at outlet relatively increases. This could be explained as follows, the increase in the air velocity reduces the residence time of air in the duct, which results in shorter time for evaporation processes.

\section{II) The effect on air dry bulb temperature at outlet}

Figures 5 and 6 describe the influence of air dry bulb temperature, relative humidity, and water temperature at inlet on the Air dry bulb temperature at outlet. Figure 5, shows that the experimental results agree well with the predicted results. The maximum difference between the experimental and theoretical results is $1.8 \%$.

Figure 5 shows the effect of the air dry bulb temperature at inlet on the air dry bulb temperature at outlet. The figure explains that as the water temperature is increased the dry bulb temperature at outlet increases for an assigned value of air dry bulb temperature at inlet. For the same water temperature, the increase in air dry bulb temperature causes certain increase in the air dry bulb temperature.

Figure 6 shows that the experimental results agree well with the calculated. The maximum difference between the experimental and theoretical obtained results is $2 \%$.

Figure 6 explains the influence of the relative humidity at inlet on the air dry bulb temperature at outlet. The air dry bulb temperature was enhanced as the water temperature increases. The air dry bulb temperature at outlet is decreased as the relative humidity at inlet increases as result of the reduction in the air dry bulb temperature at inlet.

This could be due to the fact that for the same water temperature at inlet, the relative humidity at inlet decreases as the air dry bulb temperature at inlet is increased. This will reduce the ability of air to evaporate water at higher relative humidity and lower water temperature at inlet thus, leading to a reduction in the air dry bulb temperature .

Figures $7 \mathrm{a}, \mathrm{b}$ and $\mathrm{c}$ show a good agreement between the experimental and the calculated results. The maximum difference between the experimental and theoretical obtained results is about $0.5 \%$.

Figures illustrating the effect of water temperature at inlet on the air dry bulb temperature at outlet. A slight increase in air dry bulb temperature at outlet for assigned value of air dry bulb temperature at inlet for a variation of water temperature at inlet in the range $20^{\circ} \mathrm{C}-60^{\circ} \mathrm{C}$.

It is seen in the figures that the air dry bulb temperature at outlet decreases by $7 \%$ as air velocity decreases from $1.45,1.3$ to $1.1 \mathrm{~m} / \mathrm{s}$ for air dry bulb temperature of $26.5^{\circ} \mathrm{C}$. The figures show that inlet water temperature has small effect on the outlet air dry bulb temperature.
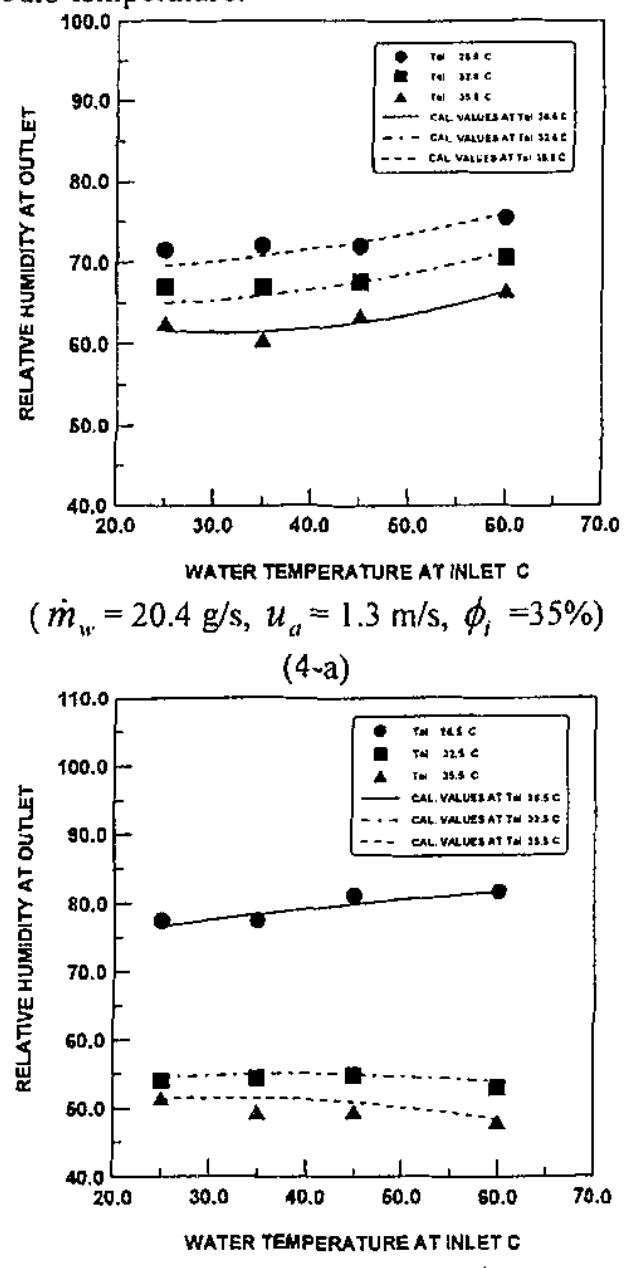

$\left(\dot{m}_{w}=20.4 \mathrm{~g} / \mathrm{s}, u_{a}=1.45 \mathrm{~m} / \mathrm{s}, \phi_{t}=35 \%\right)$

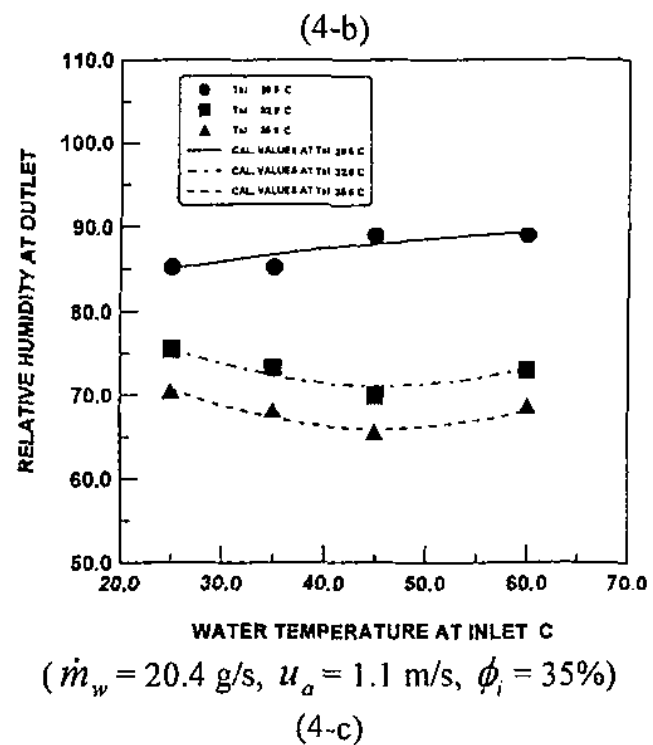

Fig 4. The effect of water temperature at inlet on the relative humidity at outlet. 


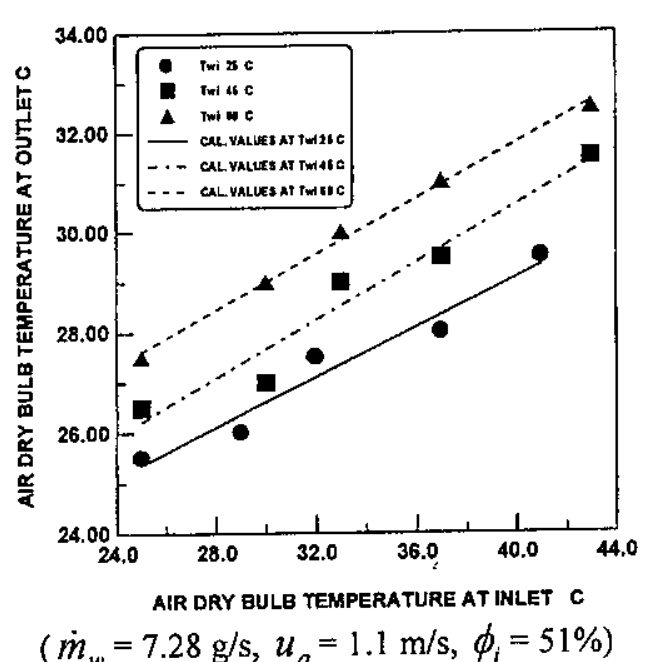

$(5-a)$

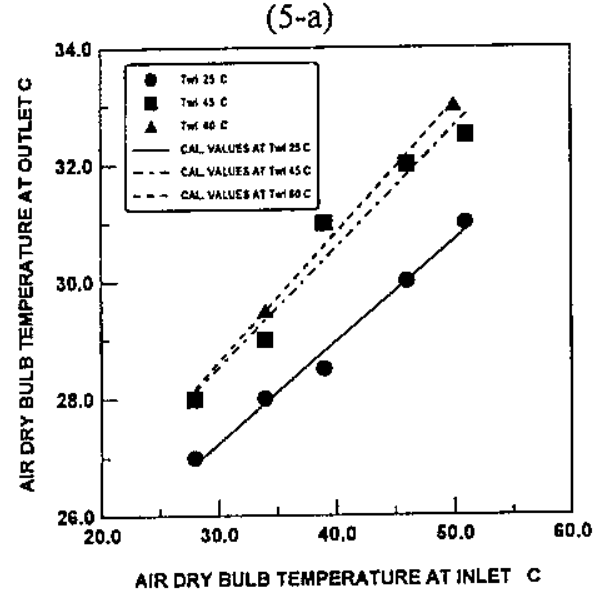

$$
\left(\dot{m}_{w}=20.4 \mathrm{~g} / \mathrm{s}, u_{a}=1.1 \mathrm{~m} / \mathrm{s}, \phi_{i}=51 \%\right)
$$

Fig 5. The effect of inlet temperature of air on the relative Humidity at outlet.

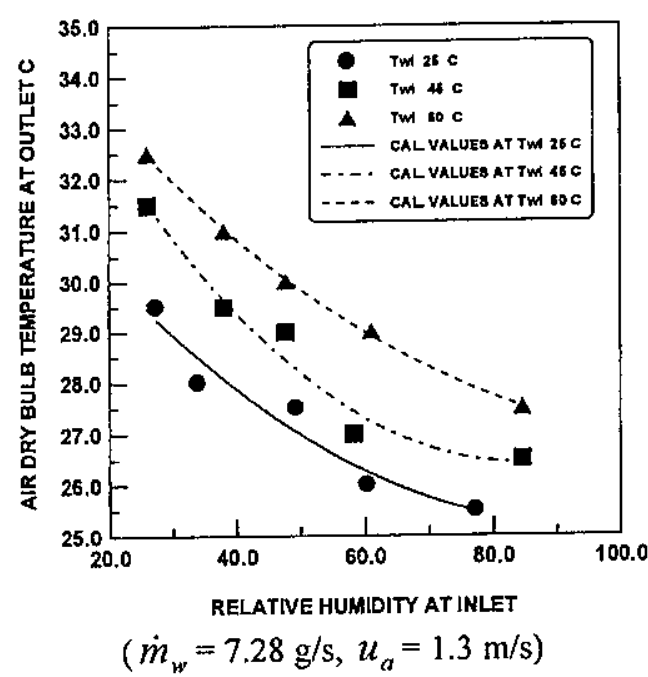

$(6-a)$

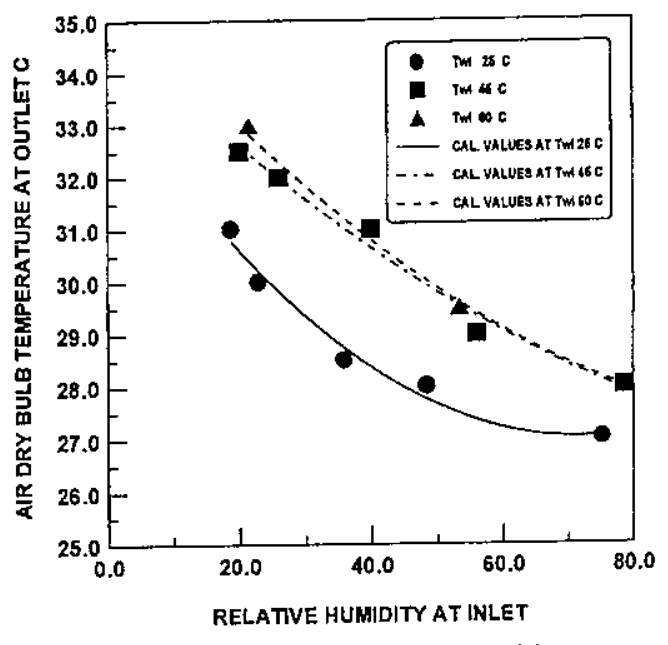

$\left(\dot{m}_{w}=20.4 \mathrm{~g} / \mathrm{s}, u_{a}=1.3 \mathrm{~m} / \mathrm{s}\right)$

(6-b)

Fig 6. The effect of relative Humidity at inlet on the air dry bulb temperature at outlet.

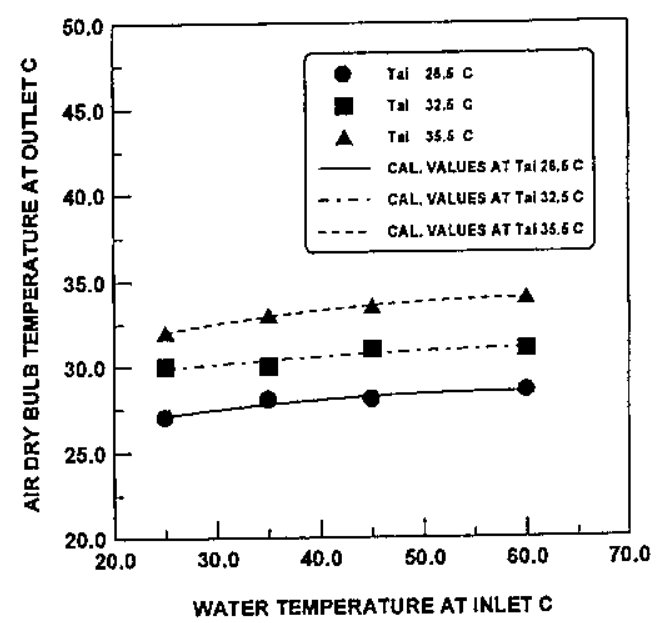

$\left(\dot{m}_{w}=20.4 \mathrm{~g} / \mathrm{s}, u_{a}=1.3 \mathrm{~m} / \mathrm{s}, \phi_{i}=41.5 \%\right)$

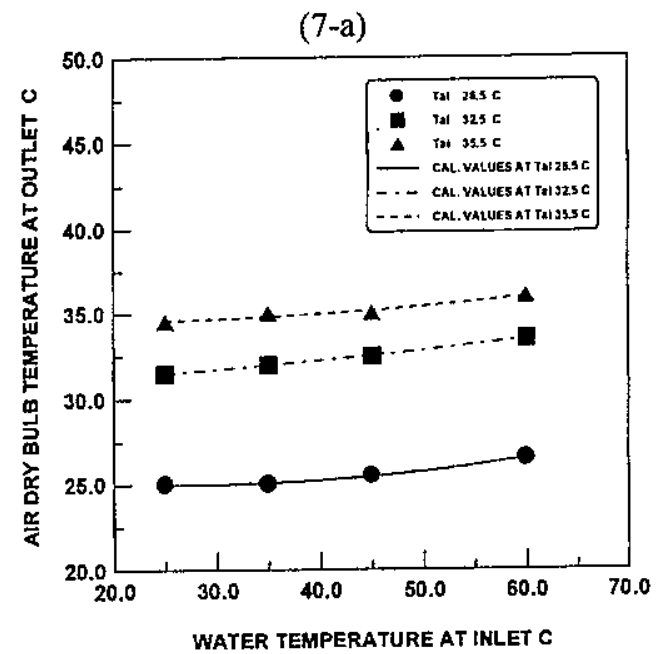

$\left(\dot{m}_{w}=20.4 \mathrm{~g} / \mathrm{s}, u_{a}=1.45 \mathrm{~m} / \mathrm{s}, \phi_{i}=41.5 \%\right)$

(7-b) 


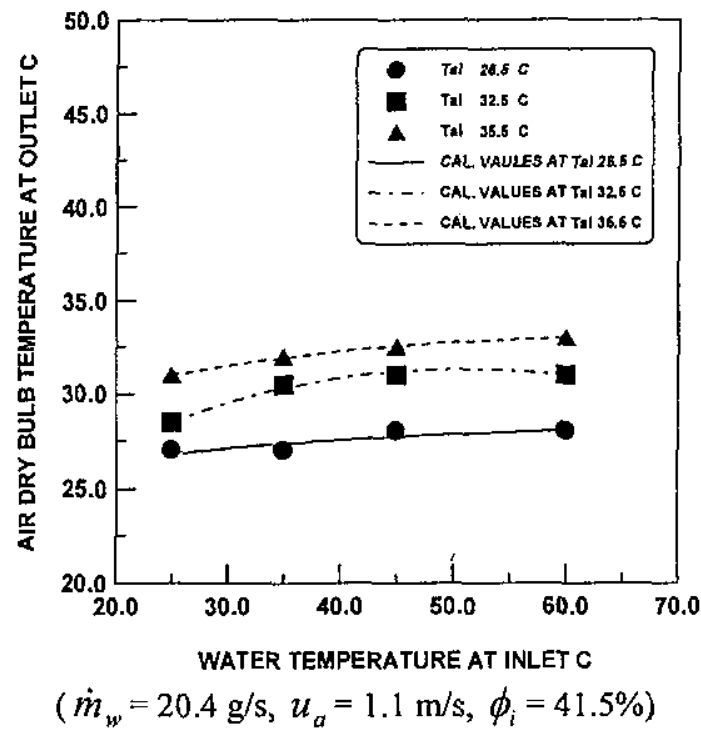

$(7-c)$

Fig 7. The effect of water temperature at inlet on the air dry bulb temperature at outlet.

\section{III) The effect on the change in absolute humidity at outlet}

The following figures show the influence of air dry bulb temperature, and water temperature at inlet on the absolute humidity of air at outlet .

A reasonable agreement between experimental and theoretical results could be observed in figure 8 . The difference between the experimental and theoretical results is not more than $5 \%$.

Figure 8 shows that a slight increase in the absolute humidity will be noticed as the air dry bulb temperature at inlet increases. Also as water temperature increases the variation of the absolute humidity also increases. This is due to the fact that the rate of water vaporization increases due to the increase of air dry bulb temperature and water temperature at inlet, so that water vapor will be increased and leads to an increase of the absolute humidity at outlet. It is seen in Figure 8-b that as water mass flow rate decreases the absolute humidity at outlet decreases. This could be interpreted as follows, as water mass flow rate is decreased the number of droplets will decrease. This will lead to a decrease in the area of mass transfer between water and air, thus causing a decrease of the rate of water vaporization. As the rate of water vaporization decreases, the absolute humidity will in turn decrease.
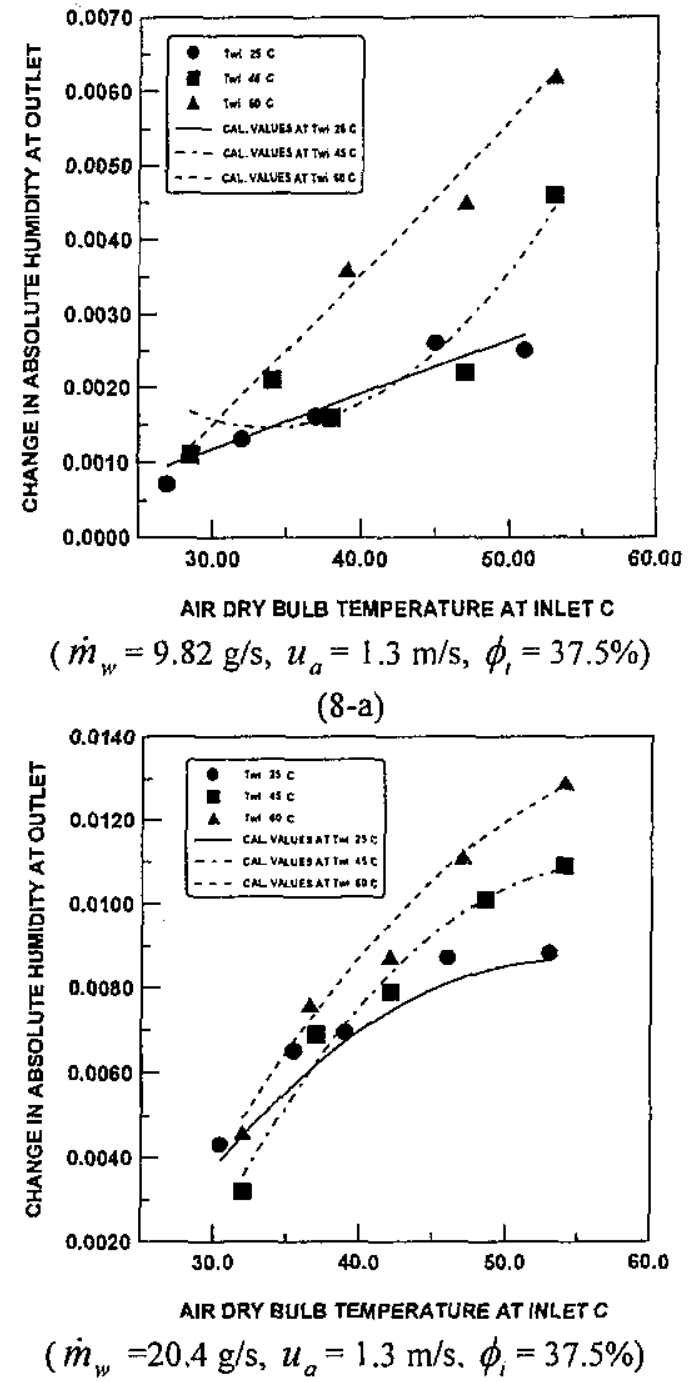

(8-6)

Fig 8. The effect of inlet temperature of air on the change in absolute humidity at outlet.

Figure 9 shows that the experimental results agree well with the calculated results. The maximum difference between the experimental and theoretical obtained results is $8.4 \%$. Figures 9 illustrate the influence of the relative humidity at inlet on absolute humidity at outlet. It could be seen that the relative humidity at inlet has a negative effect on the absolute humidity. It could be seen from these figures that as the water temperature at inlet increases, the change in absolute humidity decreases for assigned values of relative humidity at inlet. By comparing Figures 9 a, $b$ and $c$, it could be seen that the change in water mass flow rate from 20.4 to $7.28 \mathrm{~g} / \mathrm{s}$ and air velocity from 1.1 to $1.3 \mathrm{~m} / \mathrm{s}$ have slight influence on the change in absolute humidity. As mentioned previously, water vaporization will be a result of the increase in the relative humidity. Although the decrease of water mass flow rate is associated with an increase of the absolute humidity. 


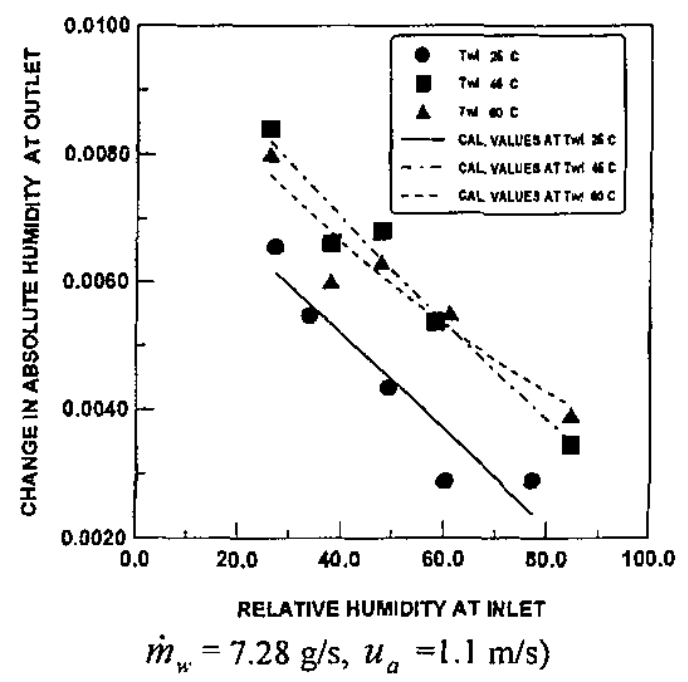

(9-a)

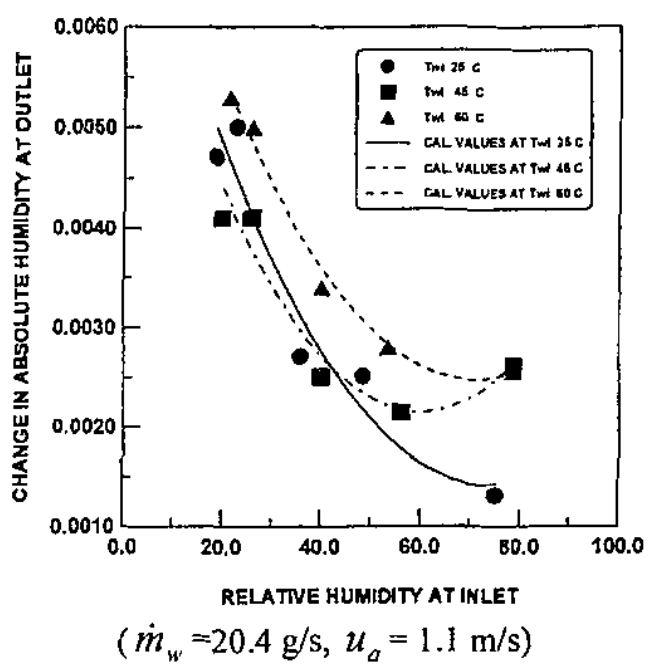

(9-b)

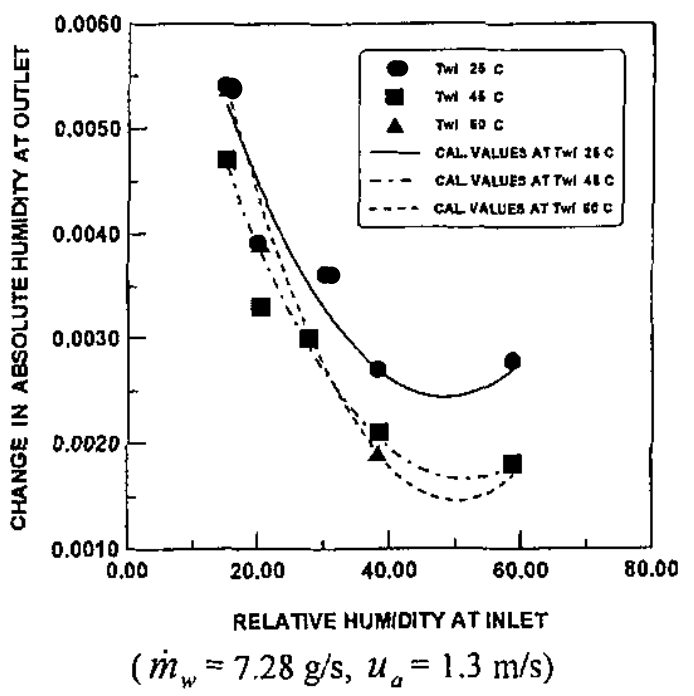

$(9-c)$

Fig. 9 The effect of the relative humidity at inlet on the change in absolute humidity at outlet.
Figures $10 \mathrm{a}, \mathrm{b}$ and $\mathrm{c}$ show the effect of water temperature at inlet on the absolute humidity. These figures reveal that the absolute humidity wil! be enhanced as the inlet air dry bulb temperature increases for the selected range of water temperature from $20^{\circ} \mathrm{C}$ to $60^{\circ} \mathrm{C}$.

By comparing the above figures it could be noticed that the increase in air velocity will lead to a reduction of the absolute humidity at outlet for a water temperature at inlet ranging from $20^{\circ} \mathrm{C}$ to $60^{\circ} \mathrm{C}$. This may be attributed to the increase in the rate of vaporization due to the increase in the water temperature which can increase the rate of vaporization of water and this could be explained as follows:

In evaporative cooler, droplets are formed by water spraying nozzles, The radii of droplets depend on the water flow rate and temperature of water flow rate, the larger values of water mass flow rate are the small of droplets because of the higher pressure drop in nozzle. So that the rate of vaporization of water will be increased due to the increase of surface area of droplets.

Water temperature has a significant effect on the surface tension which will be decreased as the water temperature increases, and leads to an increase in the rate of vaporization of water. At the same time as the air dry bulb temperature at inlet, the rate of evaporation will increase. This increase is caused by augmenting the air ability to carry water vapor as it becomes hotter.

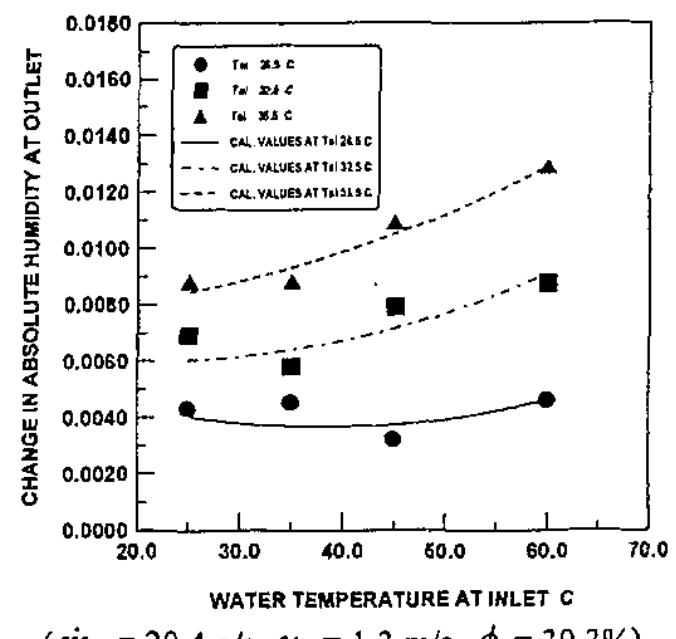

$\left(\dot{m}_{w}=20.4 \mathrm{~g} / \mathrm{s}, u_{a}=1.3 \mathrm{~m} / \mathrm{s}, \phi_{i}=39.3 \%\right)$

$(10-a)$ 


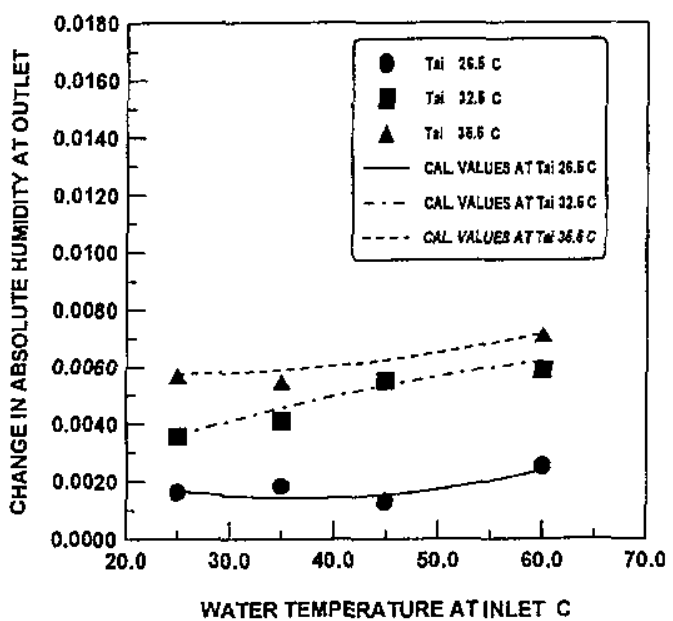

$\left(\dot{m}_{w}=20.4 \mathrm{~g} / \mathrm{s}, u_{a}=1.45 \mathrm{~m} / \mathrm{s}, \phi_{i}=39.3 \%\right)$

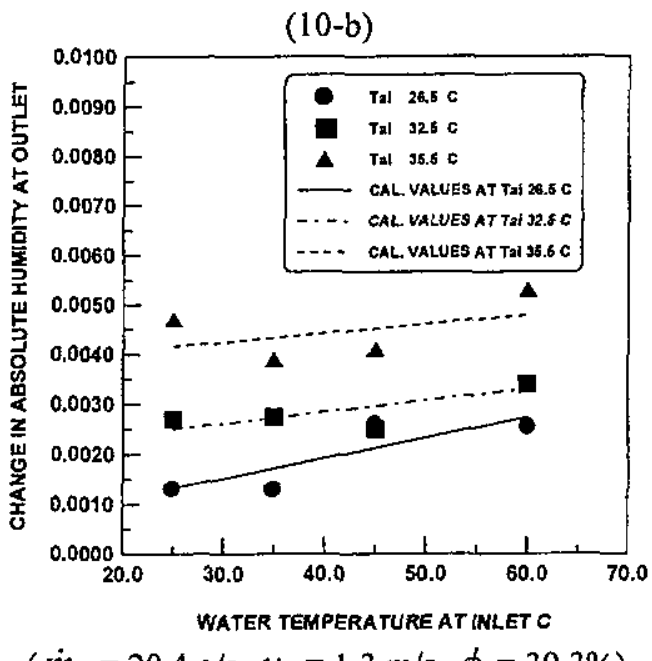

$\left(\dot{m}_{w}=20.4 \mathrm{~g} / \mathrm{s}, u_{a}=1.3 \mathrm{~m} / \mathrm{s}, \phi_{i}=39.3 \%\right)$

$(10-c)$

Fig. 10 The effect of the water temperature at inlet on the change in absolute humidity at outlet.

\section{CONCLUSIONS}

The following conclusions could be summarized from the present study on the adiabatic water spray evaporative cooler.

1. The increase in air velocity causes a decrease in both exit relative humidity and exit water temperature and an increase in the exit air temperature.

2. The increase in droplet velocity decreases the humidity of air at exit and also decreases the temperature for air and water at exit.

3. Surface area causes low rate of vaporization of water and also causes a decrease in the temperature drop for air and water.

4. The increase in the temperature of water droplets will decrease the surface tension for droplets and an increase in rate of vaporization of water.
5. Generally, a good agreement between the experimental data and the calculated results was found.

\section{REFERENCES}

[1] Fisenko S. P.; Petruchik A.I. ; Solodukhin A.D., Evaporative Cooling of Water in a Natural Draft Cooling Tower, International Journal of Heat and Mass Transfer v 45 no23 Nov 2002 p. 468394.

[2] Fisenko S.P.; Brin A.A; Petruchik A.l. ,Evaporative Cooling of Water in a Mechanical Draft Cooling Tower, International Journal of Heat and Mass Transfer. v $47 \mathrm{n} 1$ January 2004. p. 165-17.

[3] Brin A.A; Petruchik A.I.; Fisenko SP-, Mathematical Modeling of Evaporative Cooling of Water in a Mechanical-Draft Tower, Inzhenerno-Fizicheskii-Zhurnal. V. 75 , n. 6 2002, p 68-73

[4] Juwayhel Al.; Faisal I.;Al-Haddad A.A.;ShabanHabib 1.; Hisham- EI-Dessouky TA. ,Experimental Investigation of Tthe Performance of Two-Stage Evaporative Coolers, Heat-Transfer-Engineering. v $18 \mathrm{n} 2$ Apr-Jun1997, p21-33.

[5] Boris Halasz, A General Mathematical Model of Evaporative Cooling devices, Rev. Cen. Therm (1998) 37. 245-255.

[6] Pearlmutter D.; Erell E.; Etzion Y.; Meir IA.; Refining The Use of Evaporation in an Experimental Down-Draft Cool Tower, Energyand-Buildjngs, v 23 n 3 Mar 1996. p 191-197.

[7] Al-nimr M.A., Dynamic Thermal Behaviour of Cooling Towers, Energy Convers. Mgmt Vol. 39, No. 7, pp. 631-636, 1998.

[8] Kachhwaha S. S., Dhar P. L. , Kalef S. R. ,Experimental Studies and Numerical Simulation of Evaporative Cooling of Air With a Water Spray-1. Horizontal Parallel Flow ,II Horizontal Counter Flow, Int. J. Heat Mass Transfer Vol.41, No.2, pp447-464 and pp.465474, 1998.

[9] Harlow F. M., Amsden A. A , Numerical Calculation of Multiphase Fluid Flow. Journal of Computational Physics, 1975, 17, 19-52.

[10] El-Emam S. H. , Awad M. M. ,A Study on Liquid Spray Evaporation into a High Temperature Gas Stream, Mansoura Engineering Journal (mej),vol.13,no.1,June 1988.

[11] Goshayshi H. R., Missenden J.F., The Investigation of Cooling Tower Packing in Various Arrangements, Applied Thermal Engineering 20(2000)pp 69-80.

[12] Dreyer A., Erens P. J., Modelling of Cooling Tower Splash Pack, Int. J. Heat Mass Transfer. Vol. 39. No. 1. pp. 109-123, 1996. 
[13] Maiya M. P., Analysis of Modified CounterFlow Cooling Towers, Heat Recovery Systems \& CHP Vol. 15. No. 3.pp. 293-303. 1995.

[14] Majumar A.K.; Singhal A.K. ; Spalding D.B.,Numerical Modeling of Wet Cooling Towers- Partl : Mathematical and Physical Models,.Transactions of the ASME,vol.105, nov. 1983 pp 728-735.

[15] Ei-Ghalban A R.,Numerical Simulation of Adiabatic Evaporative Cooler, $12^{\text {th }}$ International Mechanical Power Engineering Conference, Mansoura Egypt 2001.

[16] EL-Dessouky T.A. ; AL-Haddad A. A. , AlJuwayhel F, Thermaland. Hydraulic Performance of a Modified Two-Stage Evaporative Cooler, Renewable Energy, ol.7,no.2,pp.165176,1996.

[17] Fisenko S.P., Petruchik A.I. ,Toward to The Control System of Mechanical Draft Cooling Tower of Film Type' International Journal of Heat and Mass Transfer, Received 5 August 2004.

[18] Jameel-Ur-Rehman Khan, Bilal Ahmed Qureshi, Syed M. Zubair, A Comprehensive Design And Performance Evaluation Study of Counter Flow Wet Cooling Towers, International Journal of Refrigeration, Received 23 September 2003; received in revised form 17 March 2004; accepted 4 April 2004.

[19] Prasad M.' Economic Upgradation and Optimal Use of Multi-Cell Crossflow Evaporative Water Cooling Tower Through Modular Performance Appraisal' Applied Thermal Engineering 24 (2004) 579-593.
[20] Sesha Girish G.V.S., Mani A., Numerical Simulation of Forced Convective Evaporation System for Tannery Effluent' International Journal of Heat and Mass Transfer 47 (2004) 1335-1346.

[21] Baker D. R. and Shryock H. A., A Comprehensive Approach to The Analysis of Cooling Tower Performance, AMSE J, Heat Transfer, 83, 1961, pp. 339-350.

[22] Webb R. L., A Critical Evaluation of Cooling Tower Designs Methodology. In Heat Transfer Equipment Design, (Edited by R. K. Shan, E. C. Subbarao and R. F. Mashelkar) pp. 547-558. Hemisphere, New York, 1988.

[23] Marseille T. J., Schliesing J. S. , Bell D. M. and Johnson B. M., Extending Cooling Tower Thermal Performance Prediction Using LiquidSide Film Resistance Model, Heat transfer engineering, 12, 1991, pp. 19-30.

[24] Kachhwaha S.S., Some Studies on Spray Type Evaporative Cooling Process. Ph.D. Thesis. Mechanical Engineering Department, I.I.T, Delhi, 1996.

[25] Linn J. D. M., Maksell S. J: and Patrick M. A. A., A Note on Heat and Mass Transfer to a Spray Droplet, Nuclear Technology, 1988,88 pp. 122-125.

[26] Jain S., Ph.D. Thesis. Mechanical Engineering Department, I.I.T., Delhi, 1994.

[27] Dewitt D.P,F.PIncropera, Fundamentals of Heat Transfer. 3rd edn. Wiley, 1991.

[28] Bird R.B.W.E.Stewart,E.N.Lightfoot, Transport Phenomenon. Wiley. New York, 1960, p. 647. 